\title{
Changes in the Whole Blood Donor Population in South-West Germany: 2010 versus 2016
}

\author{
Michael Müller-Steinhardt ${ }^{\mathrm{a}}$ Christian Weidmann $^{\mathrm{b}}$ Harald Klüter ${ }^{\mathrm{a}}$

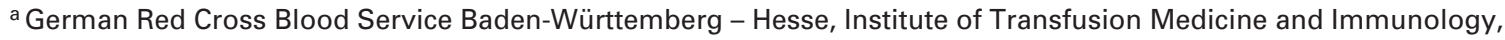 \\ Medical Faculty Mannheim, University of Heidelberg, Mannheim, Germany; \\ ${ }^{b}$ Furtwangen University, Faculty Health, Safety Society, Furtwangen, Germany
}

\section{Keywords}

Demographic change - Total whole blood donations . Mean annual donation frequency - Return probability . Donor age - Medical reasons for deferral .

First-time donors · Repeat donors

\section{Summary}

Background: In the recent past, the discrepancy between blood supply and future demand may have been overestimated. As medical progress develops rapidly, it will be essential to monitor ongoing demographic changes in the donor population regularly and to re-evaluate retention and recruiting strategies. The aim of the current study was to compare first-time donor (FTD) characteristics and their return rates. We therefore compared whole blood (WB) donations in total and the annual donation frequencies in 2010 and in 2015/2016. Furthermore, we evaluated whether over the same observation period, medical reasons for deferral underwent a change (2010 vs. 2015). Methods: The return probability of FTD within 12 months was analysed in 2010 and 2015 with respect to successful donation versus deferral and with regard to age. The total number of WB donations was investigated, and age distribution was compared between 2010, 2013 and 2016. WB donation frequencies were calculated with respect to age and gender in 2010 and 2016. In a second analysis, medical reasons for deferral were differentiated into 14 categories and a possible impact of time (2010 vs. 2015) on the respective percentage was studied. Results: We observed a significant decline of the FTD return rate from $42.5 \%$ to $38.8 \%$ in donors that successfully donated WB while the rate remained unchanged in deferred FTD. At the same time the mean FTD age decreased from $29.1 \pm 11.6$ to $28.5 \pm 11.7$ years in 2016. Analysis of total WB donations revealed an in- crease of all donations from donors $\geq 60$ years, a constant percentage from donors $<30$ years but a declining proportion of donors aged 30-59 years from 2010 to 2013 to 2016. In parallel, annual mean WB donation frequencies decreased over time. Deferrals due to travel history increased significantly from 2010 to 2015 both in FTD and repeat donors. Conclusion: There is ongoing demographic change in our WB donor population. Our data prove a need for a re-evaluation of retention and recruitment strategies since previous marketing campaigns seem to have neglected the age group 30-59 years. This must be addressed in further studies as this age group will be highly relevant for assuring future blood supplies since donor recruitment from adolescents will be limited due to declining birth rates. Furthermore, deferral due to travel history is increasing significantly. Thus we will require further studies on the possible impact on donor retention.

(c) 2017 S. Karger GmbH, Freiburg

\section{Introduction}

Currently, the population structure of many Western countries is changing sustainable due to declining birth rates on the one side and an increasing life expectancy on the other. This shift also leads to a disproportional increase of older patient groups with malignancies and chronic diseases $[1,2]$ while, in parallel, therapeutic advances in haemato-oncology such as allogeneic stem cell transplantation and increasing numbers of major surgical procedures have resulted in a steadily growing demand for blood products for a very long time $[3,4]$. The fact that a larger number of older pa-

\section{KARGER}

(๑) 2017 S. Karger GmbH, Freiburg 
tients have become eligible for these procedures has even contributed to an acceleration of this development. As the demographic change not only increases the number of patients requiring blood products but also reduces the eligible blood donor population [5], this has up to date been considered to be one of the biggest challenges for transfusion medicine in the coming two decades, requiring sustainable efforts to prevent blood shortages in many Western countries $[1,6]$.

However, current publications on blood demand and safety are heterogeneous. Although the supply of blood products has been satisfactory in the US up until now, several reports predict shortages, especially of red blood cell (RBC) concentrates, until 2030 [7], a previous study from the UK rather estimates a stable supply/demand ratio for the next 20 years [8]. However, in Germany, despite distinct regional differences, the overall blood donor population has already started to shrink since 2015 and is estimated to decrease by $25-33 \%$ until 2060 [9]. Thus, new concepts will be essential to meet future blood demands and motivate people of all age groups to donate blood. Notably, only $3-4 \%$ of the German population are currently repeat blood donors (RD) [10]. However, during the recent years it has become obvious that in addition to the demographic changes advanced concepts in transfusion practice have additional impact on the blood demand. Many efforts have been initiated to reduce the number of blood transfusions. One is the patient blood management concept, initiated as a patientcentred, multidisciplinary approach to reduce the need for allogeneic blood transfusions. Furthermore, clinical studies indicate that restrictive transfusions regimes of RBCs may not negatively influence the outcome in various patient groups versus liberal transfusion regimes [11] and the increase of less invasive treatment strategies that have become available also will require less transfusions [12].

Even though the discrepancy between blood supply and demand for the coming decade may have been overestimated, it will be essential to observe this relationship very closely in order to provide a safe and adequate blood supply in the future. Thus it was the aim of this study to closely monitor the ongoing demographic change in our donor population. As donor recruitment among adolescents will be limited in the future, we particularly focussed on first-time donor (FTD) characteristics and return behaviour in order to review current recruitment and retention concepts. Moreover, retention strategies will also be increasingly relevant for $\mathrm{RD}$. Therefore we investigated medical reasons for deferral, since deferral from whole blood (WB) donation may not only result in a temporary but also a permanent donor loss putting the donor loyalty to the test $[13,14]$. Ongoing monitoring of deferral reasons will also be essential in the future in order to permanently match information and promotion strategies concerning blood donors.

\section{Materials and Methods}

Donors and Eligibility Criteria

All data were generated from the database of the German Red Cross Blood Service Baden-Württemberg - Hesse. Further analysis was done using 11gRs (Oracle, Redwood City, CA, USA) and SAS 9.0 (SAS Institute, Inc., Cary, NC, USA) Only allogeneic WB donations, either from mobile or in-house collection sites, were considered for analysis, autologous donations were excluded. Donor selection was performed according to the national guidelines except for the donor age (FTD were admitted if younger than 65 years of age, RD if younger than 72 years of age [15]. RD were considered to be donors when they had donated at least twice within 5 years.

\section{Analysis of Return Probability of FTD}

The return probability of FTD was calculated as follows: number and percentage of individuals that returned within 12 months after a first WB donation attempt and categorized as: i) all donors, ii) donors with successful WB donations at the first attempt iii) donors with temporal deferrals at the first attempt.

Table 1. Medical reasons for deferral from WB donation in 2010 and 2015 given as percent of all deferrals; significant differences in 2015 versus 2010 are highlighted by '*'

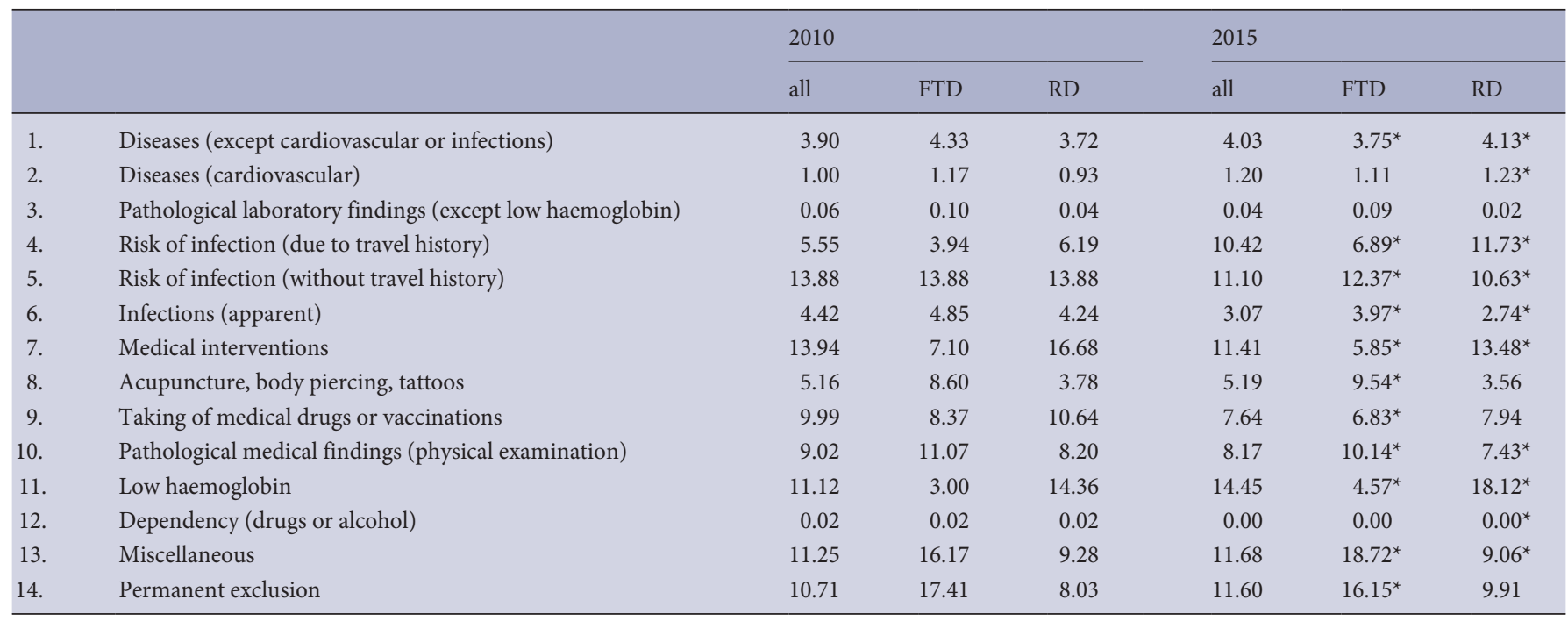



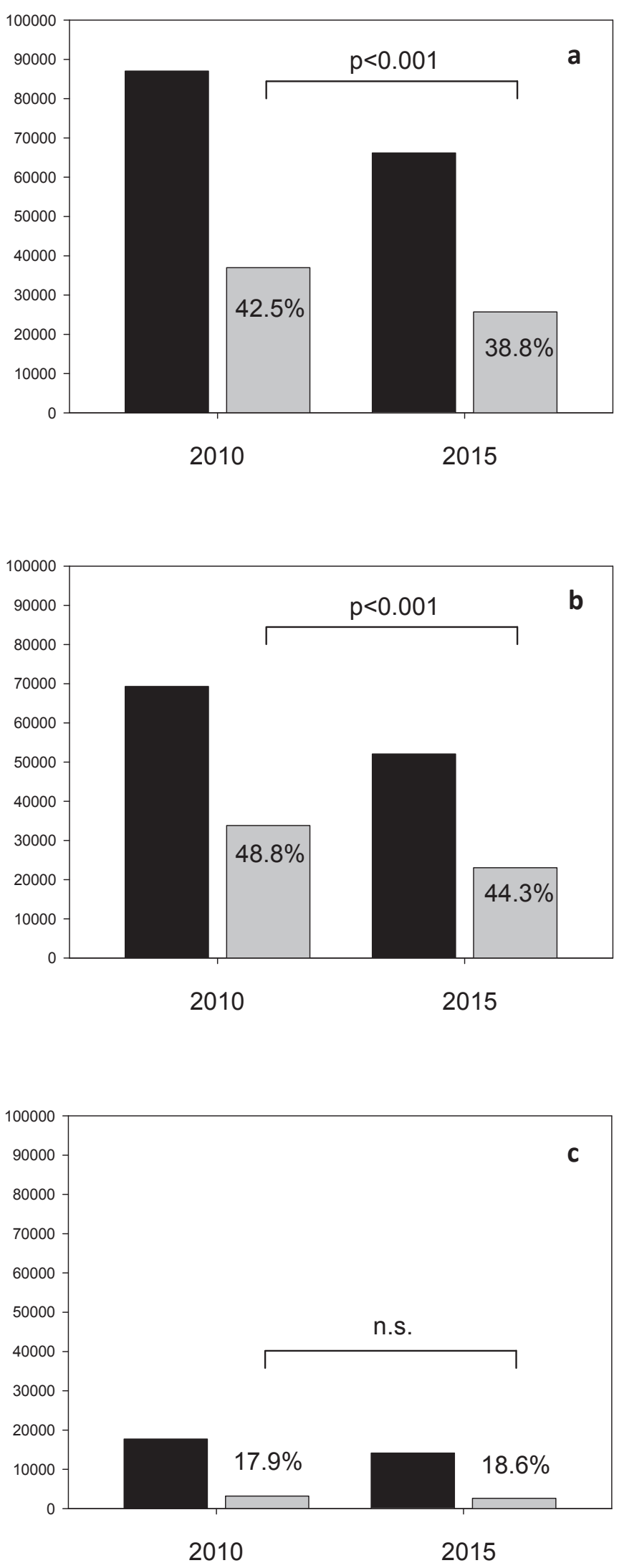

Fig. 1. a Return rate of all FTD to perform a second WB donation attempt within 12 months, 2010 versus 2015. b Return rate of FTD with successful WB donations, to perform a second WB donation attempt within 12 months, 2010 versus 2015. c Return rate of temporally deferred FTD, to perform a second WB donation attempt within 12 months, 2010 versus 2015.

\section{Determination of Annual WB Donations and Donation Frequencies}

Age (18-72 years) and sex-related total numbers of annual WB donations were obtained by considering all donations that were given between January 1, and December 31, 2010, 2013 and 2016. According to National German Guidelines, the maximum annual number of WB donations is 6 for male and 4 for female donors. For the determination of the sex- and age-related (18-72 years) donation frequency, all donors that donated at least once between January 1, and December 31, 2010 and 2016 were included in the calculation. The individual donation frequency was determined as follows: number of WB donations between the birthdays in 2009 and 2010 (donation frequency 2010) and between the birthdays in 2015 and 2016 (donation frequency 2016). Furthermore, the age of all FTD was determined, and the mean age was compared (2010 vs. 2016).

\section{Analysis of Donor Deferral Rates and Medical Reasons for Deferral}

\section{Blood Donor Questionnaire}

All WB donors were provided with educational material describing the donation process and possible risk factors potentially influencing the safety of the blood product or the donor directly. Furthermore, they had to answer detailed medical questions of the current Blood Donor Questionnaire (BDQ) of the German Red Cross Blood Service Baden-Württemberg - Hesse, approved of by the Paul-Ehrlich-Institute.

\section{Medical Reasons for Deferral}

As there are numerous different medical reasons for deferral from a WB donation, deferral reasons were classified into 14 categories for further statistical analysis (table 1). Medical reasons for deferral were analysed with respect to the year (January 1, to December 31, 2010 vs. January 1, to December 31, 2015) and donor status (FTD vs. RD).

\section{Statistical Analysis}

Statistical analyses were performed with commercially available software for personal computers (SAS software release 9.2, SAS Institute, Inc., Cary, NC, USA). For analysis of the FTD return rates and total WB donations per age group, the chi-square test for 2 or 3 categories was applied, including odds ratios and $95 \%$ confidence intervals $(95 \% \mathrm{CI})$. FTD age was compared with the Tukey-Kramer Test. In order to analyse the mean annual WB donation frequency, with respect to donor age, sex and year, Pearson's correlation coefficient was determined. The distribution of the various categories of deferral reasons was analysed performing the chi-square or the Fisher's Exact Test including odds ratios and $95 \%$ CI.

\section{Results}

\section{Return Probability of FTD}

The total number of FTD declined from 86,995 in 2010 to 66,163 in 2016, while the number of FTD that actually donated WB decreased from $69,275 / 86,995$ (2010) to $52,048 / 66,163$ (2015) and the number of temporally deferred FTD dropped from $17,720 / 86,995$ in 2010 to $14,115 / 66,163$ in 2015 . Corresponding birth rates of the 18- to 30 -year-olds in that time period (19801998) remained stable according to data of the statistical offices of Baden-Württemberg (mean \pm SD $1.43 \pm 0.05$, median 1.43) and Hesse (mean \pm SD $1.31 \pm 0.06$, median 1.31 ), while absolute numbers of 18- to 30-year-olds even increased slightly from 1,702,212 (2010) to $1,801,000$ (2015) in Baden-Württemberg and from 920,786 (2010) to 974,525 (2015) in Hesse. However, the return 

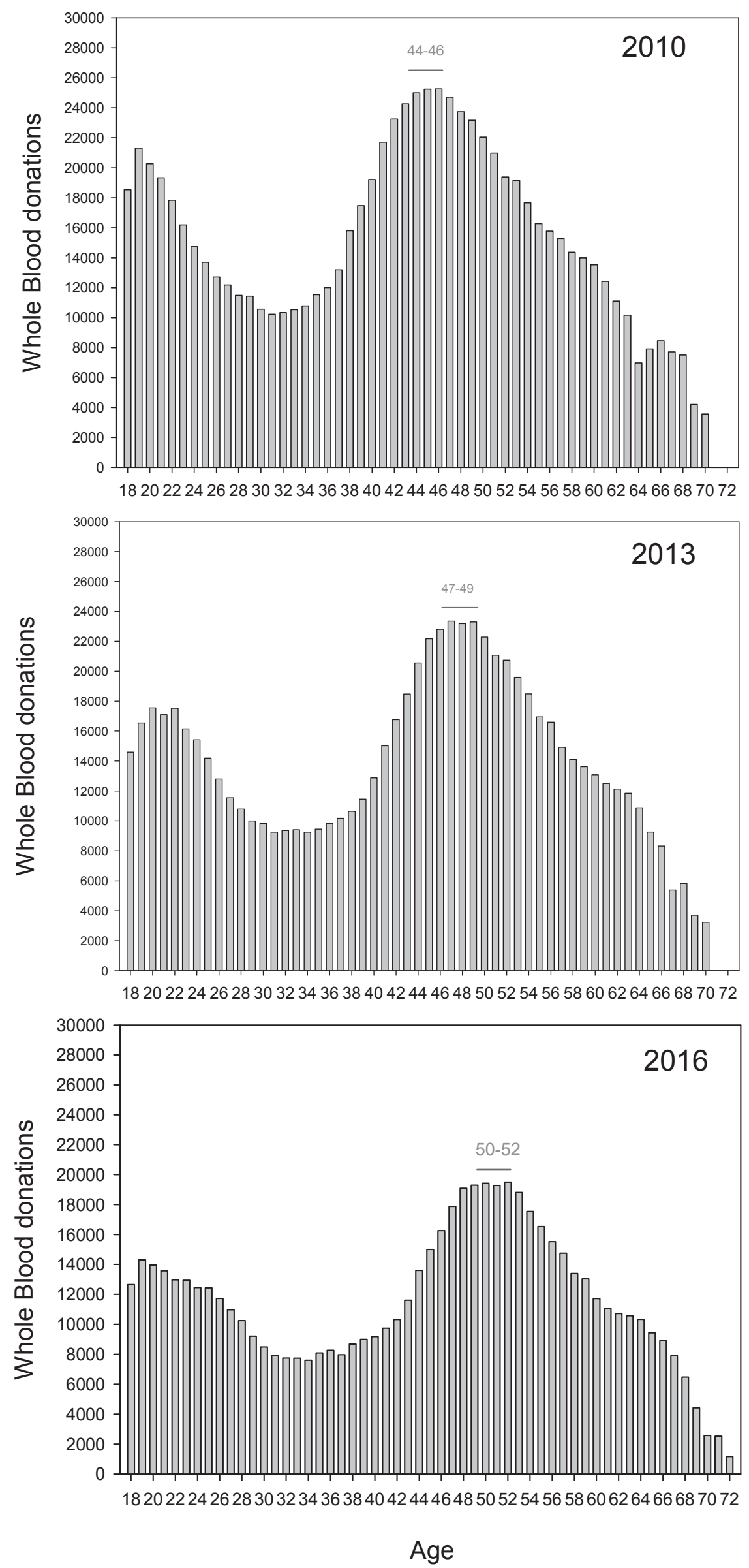

and 2016 per age group (year), the age cohort with top 3 peak values of WB donations is highlighted in red. 

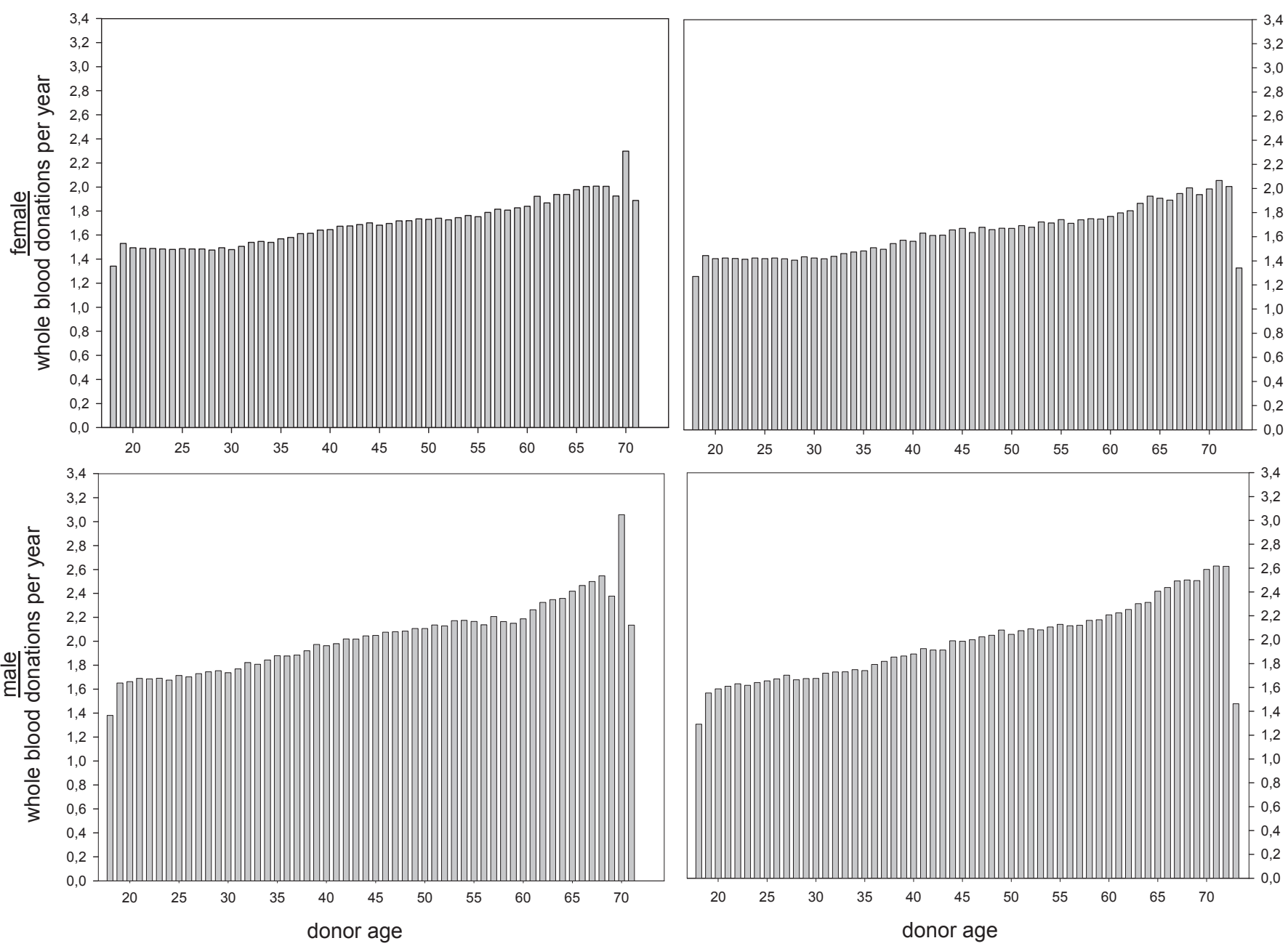

Fig. 3. Mean donation frequency for WB per year per sex and age group in 2010 and 2016.

rate of FTD to perform a then second donation within 12 months decreased significantly from $42.5 \%$ in 2010 to $38.8 \%$ in 2015 ( $\mathrm{p}<$ $0.001)$ for all donors. In parallel the return rate in FTD with successful WB donation declined from $48.8 \%$ (2010) to $44.3 \%$ (2015) ( $\mathrm{p}<0.001$ ), whereas the return rate of temporally deferred FTD donors remained unchanged at $17.9 \%$ in 2010 versus $18.6 \%$ in 2015 (fig. 1a-c).

\section{FTD Donor Age}

Mean FTD age was $29.1 \pm 11.6$ years in 2010 versus $28.5 \pm 11.7$ years in 2016 ( $\mathrm{p}<0.0001)$.

\section{Total WB Donations}

Numbers and characteristics of whole blood donations in the study period collected by our blood service in South-West Germany is given in figure 2 . While the total number of WB donations decreased constantly over time, the number of WB donations from donors 60 years of age and older increased in absolute numbers (93,543 (2010), 96,127 (2013) and 97,820 (2016)) and even more distinct as a percentage of all WB donations (11.5\% (2010), 12.9
(2013) and 15.4\% (2016); $\mathrm{p}<0.0001)$. At the same time, WB donations from donors aged 30-59 years of age declined significantly ( $\mathrm{p}<0.0001)$ in absolute $(532,843,475,463$ and 391,292$)$ and relative numbers $(65.3 \%, 63.8 \%$ and $61.5 \%)$. In parallel, the proportion of donations from donors younger than 30 years of age remained unchanged at $23.2 \%, 23.3 \%$ and $24.3 \%$ (n.s.) even though it decreased in absolute numbers $(189,642,174,222$ and 154,790). The age cohorts with the largest numbers of WB donations (top 3 peak values) were the 44- to 46-year-olds in2010, the 47- to 49-year-olds in 2013 and the 50- to 52-year-olds in 2016 (fig. 2).

\section{WB Donation Frequency}

Analysis of mean annual WB donation frequencies in WB donors revealed a strong age-correlated frequency for both females and males (2010: $\mathrm{r}=0.950, \mathrm{p}<0.0001 ; \mathrm{r}=0.930, \mathrm{p}<0.0001 ; 2016$ : $\mathrm{r}=0.884, \mathrm{p}<0.0001 ; \mathrm{r}=0.880, \mathrm{p}<0.0001$ ) (fig. 3). As expected, the overall mean annual WB donation frequencies were significantly higher in male versus female donors (2.0 vs. 1.67; $\mathrm{p}<0.0001)$. At the same time, overall mean annual WB donation frequencies decreased significantly from 2010 to 2016 (1.86 vs. 1.81 ; p < 0.0001). 


\section{Medical Reasons for Deferral}

Percentages of deferral for the different categories (1-14) are given in table 1 (2010 and 2015). Significant relative changes of deferral reasons between 2010 and 2015 are highlighted by ' ${ }^{\text {‘'. Even }}$ though the distribution of the deferral reasons varies statistically for several categories, the following variances are evident in 2015:

- FTD: foremost significant increase of deferrals due to risk of infection as a result of travel history (4).

- RD: significant increase of deferrals due to risk of infection as a result of travel history (4), low haemoglobin (11) and simultaneous decrease of deferrals due to risk of infection (without travel history) (5) and medical interventions (7).

\section{Discussion}

Until 2010, there has been a steady increase in the demand for cellular blood products in Germany [4]. In parallel, the blood donor population is shrinking substantially in many Western countries due to declining birth rates and to the fact that large cohorts of blood donors reach the age limit for WB donation $[9,16]$. As this development will even accelerate during the next 15 years [3], the expected supply gap was considered to be one of the biggest challenges for transfusion medicine in the future $[1,4]$. However, the situation is even more complex, and additional parameters such as transfusion practice or most recent medical progress [12] also impact substantially the demand of blood products.

Hence it is essential for blood donor services to analyse both the regional blood demand, considering local demographic changes of the population, i.e. potential patients and the transfusion policy of the supplied hospitals, and the demographic transformation of the blood donor population. As medical progress develops so quickly, this has to be an ongoing process in order to permanently adapt blood recovery strategies and ensure a safe and reliable blood supply.

Demographic changes affecting the blood donor population are predictable many years in advance. As the recruitment of young FTD will be limited in the coming years due to the declining birth rates, it will become increasingly relevant to improve donor retention especially of young FTD since it is known to be lower than in $\mathrm{RD}$ [13]. Therefore we compared the return behaviour of FTD in 2010 versus 2015. Even though corresponding birth rates (19801998) and absolute numbers of 18 - to 30-year-olds remained stable or even increased slightly in Baden-Württemberg and Hesse, we observed a substantial decrease of FTD from 86,995 in 2010 to 66,163 in 2015 . This may be explained by reduced donor recruitment activities due to a decreasing demand of blood products at the same time. However, we observed a significantly reduced return rate for a second WB donation attempt within the following 12 months among all WB donors (fig. 1a). Interestingly, this decrease must solely be ascribed to a reduced return rate of donors with successful WB donations, whereas the return rate of temporally deferred donors, which is as expected much lower, remained unchanged (fig. 1b, c). In parallel the mean age of FTD decreased from 29.1 years in 2010 to 28.5 years in 2015 . This observation requires further attention and should be addressed in further studies to establish a possible connection between both developments as it may be highly relevant for future FTD marketing campaigns.

In previous studies we described that the risk of adverse reactions in $\mathrm{RD}$ is age-correlated and higher in younger individuals [17]. As it is well known that adverse reactions such as syncopaltype reactions negatively impact on donor motivation and return probability $[13,14]$, it would be of great interest whether this correlation is also valid for FTD. An age-correlated risk of adverse reactions in FTD could possibly explain why we observe decreasing return rates and a decreasing mean age of FTD in parallel. However, our data indicate that younger individuals may have been recruited very effectively, which can be considered as a success, but at the same time FTD from older age groups such as those $>30$ years must not be neglected. As the age limit has been extended several times in many blood services, these cohorts may still be valuable WB donors for several decades.

In a most recent publication, it was described that in the Federal State of Mecklenburg-West Pomerania in North-East Germany the age distribution of WB donors shifted from 2005 to 2010 by 5 years [3]. Thus, we examine this finding in a larger scale in our donor population of Baden-Württemberg and Hesse as demography differs to that of the North-East of Germany. However, our data from 2010 and 2016 confirm a shift of the age cohort with the maximum 3 peak values of WB donations from 44-46 (2010) to 47-49 (2013) and 50-52 years (2016). Hence it seems to be the same baby-boomers years, i.e. 1964-1966, that contribute currently the maximum number of WB donations (fig. 2). In accordance, we observed a relative increase of WB donations from donors 60-72 years of age, affirming a continuous aging process in our donor population. In contrast, the percentage of donations from middle-aged donors (30-59) declined steadily, indicating that this age group will require more attention in the future and may have been neglected in the past when recruitment strategies and scientific interest mainly focussed on elderly $[17,18]$ or young donors [19]. Notably, donations from donors younger than 30 years of age remained unchanged at the same time. This differs from the results in the North-East of Germany, presumably due to strong migration of young people from rural areas to the industrialized areas in the South-West.

We further analysed medical reasons for deferral both in FTD and in $\mathrm{RD}$, as deferral from $\mathrm{WB}$ donation not only results in temporary but permanent donor loss $[13,14]$. Insufficient information about deferral reasons, deferral periods or the option to return may negatively impact on donor loyalty. Our results show that the distribution of deferral reasons differs significantly between FTD and RD. Besides miscellaneous and permanent exclusion, the risk of infection without travel history is the most frequent reason among FTD in 2010 and 2015. However, risk of infection due to travel history represents the fastest growing deferral category in 2015 versus 2010. In contrast, in $\mathrm{RD}$ it is low haemoglobin and medical interventions that represent the most frequent deferral reasons both in 2010 and 2015, 
but, again, it is the risk of infection due to travel history that shows the largest relative increase from 2010 to 2015, indicating a growing relevance of overseas travel for blood donation.

Our study has limitations, as it is a retrospective analysis of a supra-regional not-for-profit blood donor service in the SouthWest of Germany. Furthermore, data were collected in a period of decreasing demand for blood products. Thus comparability to other regions or other blood donor services in Germany may be limited. However, our data reveal a detectable ongoing demographic change in our WB donor population. Despite the fact that the total number of WB donations has declined from 2010 to 2016 due to a reduced demand, we also observe a declining return rate and mean age of FTD in parallel. This indicates not only that we have to revaluate our donor retention strategies for the future, but also raises the question whether FTD marketing campaigns may have neglected the age groups 30 years plus in the recent past. A declining percentage of total WB donations from donors 30-59 years from 2010 onwards underlines that this age group requires even more attention as donor recruitment from adolescents will be limited in the future. In order to permanently improve WB donor retention, it will also be relevant to investigate the impact of specific deferrals on retention as distribution of medical deferral reasons changes over time as we have shown here and thus requires constant evaluation and subsequent adaption in order to ensure an adequate and safe blood supply in the future.

\section{Acknowledgements}

The authors are grateful to Mr Ronnie Saliger for careful data extraction and subsequent analysis and to Ms. Daniela Griffiths for carefully editing the manuscript.

\section{Disclosure Statement}

The authors declared no conflict of interest.

\section{References}

1 Greinacher A, Fendrich K, Hoffmann W: Demographic changes: the impact for safe blood supply. Transfus Med Hemother 2010;37:141-148.

2 Katalinic A, Peters E, Beske F, Pritzkuleit R: Projection of morbidity 2030 and 2050 :impact for the national health system and blood supply. Transfus Med Hemother 2010;37:155-159.

3 Greinacher A, Weitmann K, Lebsa A, Alpen U, Gloger D, Stangenberg W, Kiefel V, Hoffmann W: A population-based longitudinal study on the implications of demographics on future blood supply. Transfusion 2016;56:2986-2994.

4 Seifried E, Klueter H, Weidmann C, Staudenmaier T, Schrezenmeier H, Henschler R, Greinacher A, Mueller MM: How much blood is needed? Vox Sang 2011;100: $10-21$.

5 Greinacher A, Fendrich K, Alpen U, Hoffmann W: Impact of demographic changes on the blood supply: Mecklenburg-West Pomerania as a model region for Europe. Transfusion 2007;47:395-401.

6 Volken T, Buser A, Castelli D, Fontana S, Frey BM, Rusges-Wolter I, Sarraj A, Sigle J, Thierbach J, Weingand $\mathrm{T}$, Taleghani BM: Red blood cell use in Switzerland: trends and demographic challenges. Blood Transfus 2016:1-10.

7 Zou S, Musavi F, Notari EPt, Fang CT, Group AR: Changing age distribution of the blood donor population in the United States. Transfusion 2008;48:251-257.
8 Currie CJ, Patel TC, McEwan P, Dixon S: Evaluation of the future supply and demand for blood products in the United Kingdom National Health Service. Transfus Med 2004;14:19-24.

9 Ehling M, Potzsch O: Demographic changes in Germany up to 2060 - consequences for blood donation. Transfus Med Hemother 2010;37:131-139.

10 Ritter S, Willand L, Reinhard B, Offergeld R, Hamouda O: Demography and donation frequencies of blood and plasma donor populations in Germany (in German). Bundesgesundheitsbl Gesundheitsforsch Gesundheitsschutz 2008;51:915-925.

11 Jairath V, Kahan BC, Gray A, Dore CJ, Mora A, James MW, Stanley AJ, Everett SM, Bailey AA, Dallal H, Greenaway J, Le Jeune I, Darwent M, Church N, Reckless I, Hodge R, Dyer C, Meredith S, Llewelyn C, Palmer KR, Logan RF, Travis SP, Walsh TS, Murphy MF: Restrictive versus liberal blood transfusion for acute upper gastrointestinal bleeding (TRIGGER): a pragmatic, open-label, cluster randomised feasibility trial. Lancet 2015;386:137-144.

12 Hamm CW, Arsalan M, Mack MJ: The future of transcatheter aortic valve implantation. Eur Heart J 2016;37: 803-810

13 Gemelli CN, Hayman J, Waller D: Frequent whole blood donors: understanding this population and predictors of lapse. Transfusion 2017;57:108-114.
14 Zou S, Musavi F, Notari EP, Rios JA, Trouern-Trend J, Fang CT: Donor deferral and resulting donor loss at the American Red Cross Blood Services, 2001 through 2006. Transfusion 2008;48:2531-2539.

15 Paul-Ehrlich-Institut: Richtlinien zur Gewinnung von Blut und Blutbestandteilen und zur Anwendung von Blutprodukten (Hämotherapie). Cologne, Deutscher Ärzte-Verlag, 2010.

16 Crawford SO, Reich NG, An MW, Brookmeyer R, Louis TA, Nelson KE, Notari EP, Trouern-Trend J, Zou S: Regional and temporal variation in American Red Cross blood donations, 1995 to 2005. Transfusion 2008;48:1576-1583.

17 Muller-Steinhardt M, Muller-Kuller T, Weiss C, Menzel D, Wiesneth M, Seifried E, Kluter H: Safety and frequency of whole blood donations from elderly donors. Vox Sang 2012;102:134-139.

18 Zeiler T, Lander-Kox J, Alt T: Blood donation by elderly repeat blood donors. Transfus Med Hemother 2014;41:242-250.

19 Masser B, Smith G, Williams LA: Donor research in Australia: challenges and promise. Transfus Med Hemother 2014;41:296-301 